\title{
Sistemas de coordenação de ordens: revisão, classificação, funcionamento e aplicabilidade
}

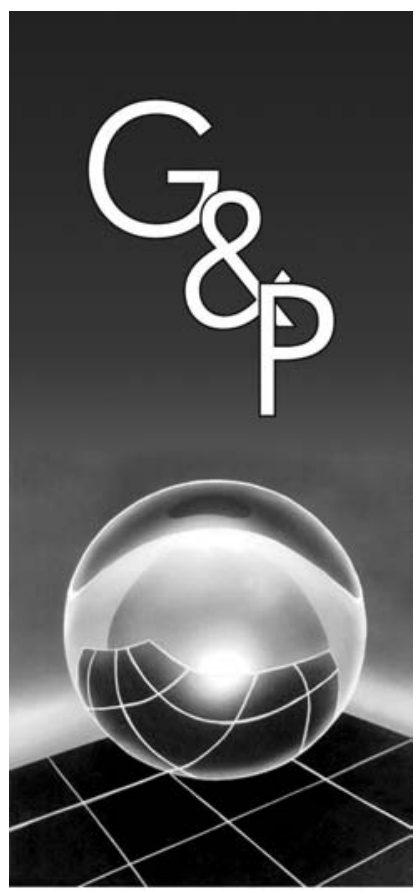

Flávio Cesar Faria Fernandes

Moacir Godinho Filho

\begin{abstract}
Resumo
O foco deste trabalho são os ordering systems, os quais são sistemas de informação que programam ou organizam as necessidades em termos de componentes e materiais elou controlam a emissão/liberação das ordens de produção e compra, podendo conter ou não regras de seqüenciamento das ordens. Dentro deste contexto, o presente artigo tem por objetivos: apresentar uma nova nomenclatura para os ordering systems, sistemas de coordenação de ordens de produção e compra (SCO); apresentar uma tipologia que permita classificar os diversos sistemas de forma racional; destacar alguns sistemas altamente promissores em termos de aplicação e que são relativamente desconhecidos no Brasil e, trazer à tona um tema importantíssimo dentro do planejamento e controle da produção $(P C P)$ e que está um tanto esquecido na literatura científica nacional.
\end{abstract}

Palavras-chave: Controle da produção. Ordering systems. Sistemas de coordenação de ordens de produção e compra. Revisão. Classificação.

\section{Introdução}

O PCP (Planejamento e Controle da Produção) envolve uma série de decisões com o objetivo de definir o que, quanto e quando produzir e comprar, além dos recursos a serem utilizados (CORREA et al., 2001). Existe muita controvérsia na literatura a respeito dos horizontes de planejamento das atividades e do escopo do PCP. Neste trabalho entendemos, como em Fernandes (1991), que o Planejamento da Produção (PP) está relacionado às atividades de médio prazo (em geral entre 3 e 18 meses) e assim, toma decisões de intenção (para não sermos pegos desprevenidos no futuro, por exemplo por falta de capacidade) na forma agregada, em termos de: a) o que produzir, comprar e entregar; b) quanto produzir, comprar e entregar; c) quando produzir, comprar e entregar; e d) quem e/ou onde e/ou como produzir. Já o controle da produção $(\mathrm{CP})$ pode ser definido como a atividade gerencial responsável por regular (programar, coordenar, organizar, dirigir e monitorar), em curto prazo (geralmente até 3 meses), o fluxo de materiais em um sistema de produção por meio de informações, regras de controle e/ou decisões para execução na forma de programação a ser implementada. Esta definição para o CP está entre as definições extremas de autores tais como, Correa et al.
(2001) que implicitamente entendem que para regular o fluxo de materiais é necessário programar, e assim, controle é monitoramento e realimentação e, autores, tais como Burbidge (1990), que entendem que o CP engloba inclusive o planejamento da produção. As decisões do âmbito do CP objetivam basicamente responder às mesmas questões já enunciadas anteriormente quando tratamos do PP, porém estas decisões têm objetivos diferentes, são detalhadas, desagregadas e tomadas em geral com pouca antecedência. As quatro principais atividades do CP são: a) programar a produção em termos de itens finais (elaborando um programa denominado Programa Mestre de Produção - MPS); b) programar ou organizar/ explodir as necessidades em termos de componentes e materiais; c) controlar a emissão/liberação das ordens de produção e compra, determinando se deve liberar as ordens e quando (atividade chamada na literatura de revisão e liberação de ordens - ORR); e d) programar/ seqüenciar as tarefas nas máquinas (na literatura esta atividade é chamada por alguns autores de dispatching e por outros scheduling); para uma discussão sobre estes dois termos ver Melnyk et al. (1986). 
Referente às atividades (b); (c); e (d), muitos sistemas se propõem a realizar uma, duas ou até mesmo as três atividades. Burbidge (1990) denomina estes sistemas de ordering systems. Dada sua importância para o controle da produção, os ordering systems são muitas vezes denominados sistemas de controle da produção, ou até mesmo, por abuso de linguagem, de Sistemas de Planejamento e controle da produção, ou ainda, sistemas de gestão da produção.

O presente trabalho tem por objetivo apresentar uma nova nomenclatura para os ordering systems, bem como uma classificação completa a respeito de uma revisão da literatura sobre os ordering systems atualmente existentes. Este trabalho também mostra resumidamente a lógica de funcionamento e aplicação destes sistemas e principais referências para estudos focados em um sistema em particular. Dessa forma, por meio de um melhor entendimento das características de funcionamento e aplicabilidade dos ordering systems, este trabalho pretende contribuir para uma melhor escolha destes sistemas na prática.

Na seção 2 é proposta uma nova nomenclatura para os ordering systems, bem como sua classificação. Na seção 3 é mostrada a lógica de funcionamento e aplicação de cada ordering system encontrado na revisão da literatura. Na seção 4 são tecidas algumas conclusões.

\section{Uma nova nomenclatura, revisão e classificação dos ordering systems existentes na literatura}

Ordering foi traduzido por Zaccarelli (1987) por Emissão de Ordens. O inconveniente desta tradução é subentender que se trata do processo de preencher uma papeleta dizendo qual(is) peça(s) deverá(ão) ser feita(s), qual a quantidade, qual a data devida, qual a data de liberação, etc. Na realidade isso é apenas uma última etapa do Ordering. Aliás, hoje, com os computadores, essa papeleta passa a ser um arquivo que pode ser enviado, por exemplo, por meio da internet ou intranet ou EDI.

Outra possível tradução seria programação das necessidades de compra e produção. O inconveniente é pensar que só existe um ordering system possível, o MRP (material requirements planning; que na realidade deveria se chamar materials requirements scheduling).

Devido a estes inconvenientes propomos um nome que espelhe melhor o que fazem os Ordering Systems nos sistemas produtivos atuais: sistemas de coordenação de ordens de produção e compra (SCO). Um sistema de coordenação de ordens programa ou organiza/explode as necessidades em termos de componentes e materiais, e/ou controla a emissão/liberação das ordens de produção e compra, e/ou programa/seqüencia as tarefas nas máquinas. Portanto, um SCO coordena as ordens de produção e de compra no chão de fábrica. A partir daqui passamos a denominar os ordering systems como SCO.

Sob o ponto de vista gerencial, vale a pena destacar a importância da coordenação. Gerir compreende 4 grupos de atividades (Figura 1).

A atividade hachurada é vital. É a coordenação que é composta por três atividades fundamentais: um pouco de planejamento, muito de controle e algo de organização.

Ao planejar tomam-se decisões de intenção para não sermos pegos desprevenidos no futuro. São decisões, por exemplo, sobre qual é o objetivo que desejamos atingir, quais atividades deverão ser consideradas, e tudo isto baseado em previsões que poderão ser de longo ou médio prazo. Visualiza-se o que vai ser o futuro e o que queremos que aconteça no futuro. Quanto mais informações qualitativas e quantitativas obtidas de um ramo de atividade, melhores serão nossas previsões, e assim melhores nossas decisões de longo e médio prazo, o que nos dará um norte para nossas decisões de curto prazo.

Ao controlar tomam-se decisões para execução. O controle da produção pode ser conseguido ao fazermos uma programação ou ao definirmos/adotarmos regras de controle, ao monitorarmos os resultados, ao compararmos o real com o programado ou esperado, e ao realimentarmos (feedback) as informações de modo que ações corretivas ou preventivas sejam tomadas, de modo que distorções de qualquer natureza (por exemplo, imprevistos) sejam contornadas e os objetivos finais sejam atingidos.

Organizar é pôr os pingos nos is; é definir uma estrutura hierárquica (rígida ou flexível, centralizada ou descentralizada, top-down ou down-up, etc) definindo quem é responsável por quais atividades, e qual a relação de interação e/ou subordinação entre essas pessoas.

Entre outras coisas, um sistema de coordenação de ordens gera as ordens. Ordens são informações que nos dizem o que, quanto, quando, quem e como deve ser executado.

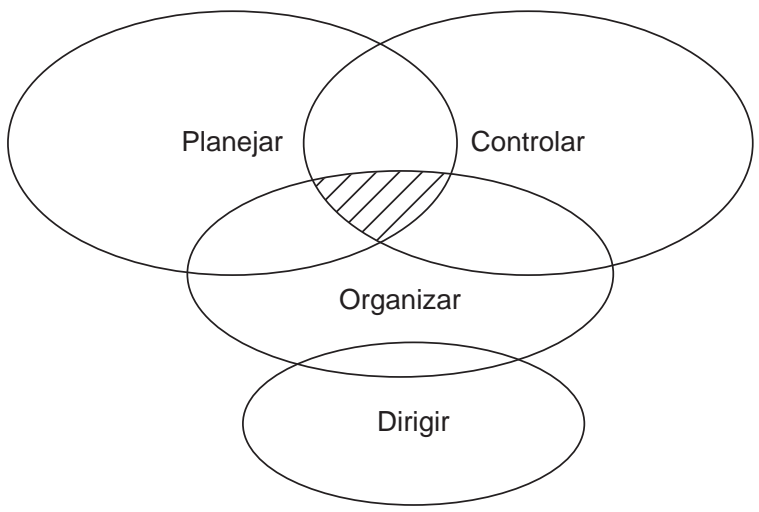

Figura 1. Gestão = planejamento + controle + organização + direção. 
Neste trabalho foi realizada uma revisão da literatura sobre SCO, a qual identificou 17 diferentes sistemas. A revisão da literatura é caracterizada, quanto aos meios, como uma pesquisa do tipo bibliográfica (VERGARA, 2004). A revisão da literatura realizada neste trabalho teve por objetivo integrar e sumarizar o estado da arte a respeito dos SCO. Portanto, esta revisão tem características de uma revisão da literatura do tipo integrativa, de acordo com Neuman (2003). Neste ponto uma observação se faz necessária: a revisão apresentada neste trabalho trata dos SCO como aqui definidos, e não de técnicas que se preocupam somente com a liberação de ordens (chamados ORR). Para revisões sobre os ORR, ver Wisner (1994); Bergamaschi et al. (1997); Sabuncuoglu e Karapinar (1999).

Para ter um conhecimento geral sobre um assunto, uma classificação é uma ferramenta essencial, uma vez que a classificação é a base do conhecimento científico (GOOD, 1965). A literatura classifica os SCO de acordo com diversos critérios. Exemplos destas classificações são:

a) classificação quanto à variável de controle primária do sistema => Hopp e Spearman (1996) fazem uma distinção com relação a esta característica dividindo os sistemas em: a) sistemas com variável de controle primária o WIP (o sistema controla o WIP - estoque em processo - e observa a taxa de saída do sistema); b) sistemas com variável de controle primária à taxa de saída (o sistema controla a taxa de saída e observa o WIP);

b) classificação quanto ao nível de agregação do sistema $=>$ Lodding et al. (2003) classificam os sistemas de acordo com este critério em: a) sistemas centralizados (se o nível de WIP e conseqüentemente os leadtimes e a utilização dos centros de trabalho são determinados em um nível de controle centralizado; por exemplo, um departamento de PCP); b) sistemas descentralizados (se o nível de WIP e conseqüentemente os leadtimes e a utilização dos centros de trabalho são determinados por meio de loops de controle entre os centros de produção);

c) classificação quanto à área de aplicação do sistema $\Rightarrow$ esta classificação aparece em muitos artigos e livros, por exemplo, Sipper e Bulfin (1997) e Slack et al. (2002). Ela caracteriza o sistema com relação à sua adequação em ambientes com alta ou baixa variedade de produtos e também a ambientes com fluxo de materiais mais complexos ou menos complexos; e

d) classificação relacionando o fluxo de materiais e de informação $=>$ diz-se que o sistema puxa a produção se ambos os fluxos caminham em direções opostas e, empurra a produção se ambos os fluxos têm a mesma direção (BONNEY et al., 1999).
Outra importante classificação é a de Burbidge (1988), o qual dividiu os SCO em três grandes grupos: a) sistemas para fazer de acordo com o pedido; b) sistemas de estoque controlado (quando as decisões de produção se baseiam nos níveis de estoque); e c) sistemas de fluxo controlado (quando as decisões são baseadas na conversão do MPS para necessidades de itens componentes).

Nossa proposta consiste em duas modificações da classificação de Burbidge: a) alterar a nomenclatura; e b) acrescentar um quarto grupo, o dos sistemas híbridos, onde há simultaneamente alguma regra de controle com base no nível de estoque, usada em pelo menos um estágio produtivo e, pelo menos um estágio produtivo é programado pelo departamento de PCP.

A seguir é apresentada a classificação proposta, alocando em cada uma das quatro categorias os SCO encontrados na revisão da literatura realizada.

Grupo A) Sistemas de pedido controlado: é impossível manter estoques de produtos finais. Compreendem:

a) sistema de programação por contrato; e

b) sistema de alocação de carga por encomenda.

Grupo B) Sistemas controlados pelo nível de estoque (CNE): nestes sistemas as decisões são baseadas no nível de estoque, o qual puxa a produção. Compreendem:

a) sistema de revisão contínua (outros nomes que aparecem na literatura: Sistema de duas gavetas, Sistema de ponto de reposição, Sistema de estoque mínimo, etc.);

b) sistema de revisão periódica;

c) sistema CONWIP CNE; e

d) sistema Kanban CNE.

Grupo C) Sistemas de Fluxo Programado: estes sistemas são baseados diretamente ou indiretamente na transformação das necessidades do MPS (Programa Mestre de Produção: programação em termos de itens finais) em necessidades de itens componentes por um departamento de PCP centralizado. Além disso, o fluxo de materiais segue a mesma direção do fluxo de informações, ou seja, a produção é empurrada. Comportam os seguintes sistemas:

a) sistema de estoque base;

b) PBC (period batch control);

c) MRP; e

d) OPT (optimized production technology).

Obs: Outros dois sistemas (sistema dos lotes componentes e sistema do lote-padrão), mostrados em Zacarelli (1987) e Burbidge (1988), também se encontram dentro desta classe, porém não serão mostrados por se encontrarem atualmente em desuso. 
grupo D) sistemas híbridos: Têm características dos sistemas das classes B e C.

a) sistema de controle MaxMin;

b) sistema CONWIP H;

c) sistema Kanban $\mathrm{H}$;

d) sistema DBR: drum (tambor), buffer (pulmão), rope (corda);

e) sistema DEWIP (descentralized work in process);

f) sistema LOOR (load oriented order release); $\mathrm{e}$

g) sistema POLCA (paired-cell overlapping loops of cards with authorization);

\section{A lógica de funcionamento e aplicabilidade dos SCO}

Nesta seção apresentamos a lógica de funcionamento e aplicabilidade de cada um dos SCO classificados na seção 2, dando destaque ao PBC, importantíssimo no controle de sistemas de produção semi-repetitivos (e pouco conhecido no Brasil) e, aos sistemas híbridos recentes, já que são pouco conhecidos e já que todos os sistemas recentemente criados são híbridos e a tendência é que os sistemas a serem desenvolvidos nos próximos anos também sejam híbridos.

\subsection{Sistema de programação por contrato}

Este sistema é usado para coordenar as ordens no caso de produtos complexos sob encomenda feitos de acordo com projetos especiais, por exemplo: construção de uma ponte, montagem de uma refinaria de petróleo, fabricação de uma grande máquina-ferramenta especial. $\mathrm{O}$ contrato desse grande projeto é dividido em atividades, incluindo geralmente atividades desde o projeto até a obtenção de pequenos componentes, e devem-se programar as datas de término ou entrega de cada atividade/item de tal forma que: o contrato seja concluído até a sua data de término; o contrato não imobilize mais capital do que o cliente possui; o contrato não custe mais do que o preço combinado. Portanto, o sistema de programação por contrato é utilizado para tratar sistemas de produção que produzem produtos de grande complexidade, fabricados sob encomenda. Basicamente esta coordenação segue algumas etapas, que vão desde o projeto do produto e de seus componentes até a emissão efetiva das ordens de fabricação de todos os componentes. Este sistema envolve também a elaboração de cronogramas (neste passo são úteis as técnicas utilizadas: PERT (program evaluation and review technique) e CPM (critical path method), o planejamento de métodos de produção, a programação de operações e materiais, e análises de capacidade/alocações de cargas. Referências sobre o assunto são os trabalhos de Burbidge (1988) e Zacarelli (1987).

\subsection{Sistema de alocação de carga por encomenda}

Aplica-se ao sistema de produção não repetitivo (e, portanto, a produção é sob encomenda), e as encomendas são itens indivisíveis e a necessidade dos clientes é imprevisível. Uma oficina de usinagem de peças de automóveis antigos é um exemplo de aplicação possível deste sistema.

A principal tarefa do sistema de alocação de carga por encomenda é reemitir internamente os pedidos dos clientes na forma de ordens de fabricação, requisições de compra e requisições de ferramentas. O principal problema é manter um registro preciso do saldo de carga em cada centro produtivo, ou pelo menos nos centros produtivos críticos, de forma que os prazos de entrega possam ser definidos de maneira correta e o trabalho possa ser programado eficientemente para cumprir os prazos prometidos. Estimar prazos é crucial e para isso é muito útil preparar um gráfico de Gantt com a alocação de cargas pelo menos no gargalo dos centros produtivos.

Referências sobre este sistema são os trabalhos de Burbidge (1988) e Zacarelli (1987).

\subsection{Sistema de revisão contínua}

A lógica deste sistema é emitir uma ordem de $\mathrm{Q}$ unidades quando o nível de estoque cai abaixo de um determinado nível $P$.

Muitos autores defendem o uso do sistema de revisão contínua em situações particulares. Por exemplo, Burbidge (1975) acredita que ele pode ser usado eficientemente para itens de demanda independente, classe $\mathrm{C} \mathrm{e}$ itens comprados, particularmente se são peças comuns e têm um baixo risco de obsolescência. Hautaniemi \& Pirttilä (1999) concordam com esta afirmação acrescentando que o sistema de revisão contínua também serve para controlar itens classe A no caso em que o leadtime de fornecimento é muito longo, a demanda é baixa e de difícil previsão, (esta afirmação é suportada por JACOBS; WHYBARK, 1992, para os quais se a previsão apresenta erros e a demanda é flutuante o sistema de revisão contínua consegue resultados melhores que o MRP com menor esforço). Schonberger (1983) defende o sistema de revisão contínua quando for extremamente difícil relacionar as necessidades dos componentes com as do produto final, devido a, por exemplo, grandes diferenças dos leadtimes dos vários componentes. De acordo com Jonsson e Mattsson (2003) este sistema é mais adequado para ambientes que trabalham com produtos padronizados feitos por lotes.

Na literatura, o sistema de revisão contínua ainda é fonte de estudos e proposta de variações para situações específicas: Lian e Liu (2001) trabalham com sistemas de revisão contínua com itens perecíveis; Salameh et al. (2003) tratam do sistema de revisão contínua quando 
o comprador tem opção de adiar o pagamento. Outros trabalhos atuais que tratam deste sistema: GhalebsazJeddi et al. (2004); Duran et al. (2004); e Wu (2004). Uma variante do sistema de revisão contínua é o chamado sistema CTP (cover time planning = planejamento baseado no tempo de cobertura), também denominado run-out planning. Neste sistema faz-se um pedido de reposição sempre que a soma do leadtime de reposição com o tempo de segurança for maior ou igual ao tempo de esgotamento (número de dias de estoque considerando a demanda esperada). Portanto, a variável de decisão neste sistema é o tempo, ao invés da quantidade no sistema de revisão contínua tradicional. O sistema CTP é uma técnica razoavelmente nova, porém já utilizada em empresas em alguns países do mundo, como por exemplo, a Suécia, conforme mostram Jonsson e Mattsson (2002). Os ambientes adequados para o CTP são basicamente os mesmos do sistema de revisão contínua (JONSSON; MATTSSON, 2003).

\subsection{Sistema de revisão periódica}

Neste sistema em intervalos constantes de tempo (por exemplo, um mês) são emitidas ordens (geralmente de compra) dos itens solicitados, por exemplo, a um mesmo distribuidor, sendo que a quantidade solicitada de cada item é igual a um valor de referência $\mathrm{M}$ menos a quantidade de estoque em mãos do item em questão. A maneira correta de determinar o valor de M é através da seguinte Equação estocástica:

$$
\text { Prob }\left(D_{L+t} \leq M\right)=\text { nível de serviço }
$$

em que $\mathrm{D}_{\mathrm{L}+\mathrm{t}}=$ demanda durante o leadtime de suprimento mais o tempo de revisão.

Com relação à aplicabilidade, trata-se de um sistema adequado para itens $\mathrm{C}$ adquiridos no mesmo momento (por exemplo, no primeiro dia útil de cada semana) de um mesmo fornecedor.

$\mathrm{Na}$ literatura existe uma série de trabalhos atuais que estudam o sistema de revisão periódica em situações específicas: Gavirnesi (2004) trata do sistema de revisão periódica quando os custos de compra são flutuantes (por exemplo, devido ao câmbio); Maddah et al. (2004) estudam este sistema quando são permitidos atrasos no pagamento; outros trabalhos são: Urban (2005); Ouyang et al. (2003); Pyke et al. (2003); Chiang (2003); dentre outros.

\subsection{Sistema Kanban CNE}

Aqui denomina-se Kanban CNE as variações do Kanban que seguem a lógica na qual as decisões (inclusive no último estágio produtivo) são baseadas no nível de estoque. Dentro deste contexto tem-se duas principais variações: a) Kanban CNE de duplo cartão; e b) Kanban CNE somente com cartão de ordem de produção. O caso (a) é o sistema original criado na Toyota, está detalhado em Monden (1993) e opera com dois tipos de cartão: o T (de transporte, outros nomes: requisição, movimentação e transferência); e o $\mathrm{P}$ (de ordem de produção). O funcionamento do caso (b) está ilustrado na Figura 2.

No caso do sistema Kanban com apenas o cartão P, o operador inicia a produção a partir de uma prioridade estabelecida por um painel com faixas de diferentes cores (usualmente vermelhas, amarelas e verdes). Tendo esta prioridade, este operador pega o material necessário que é fornecido por estação de trabalho anterior e coloca no painel desta operação anterior o cartão P.

O cartão Kanban pode assumir várias formas: etiqueta, anel, placa, etc., e existe até o Kanban eletrônico para estações de trabalho distantes (BOSE; RAO, 1988).

Com relação aos ambientes propícios para a utilização do Kanban, Gelders e Wassenhöve (1985) são taxativos em afirmar que se as condições para que o sistema Kanban funcione bem estiverem presentes, ele é o sistema ideal. Estas condições são bastante conhecidas na literatura: baixos tempos de set up, baixa variedade de itens, e demanda relativamente estável. (WHITE; PRYBUTOK, 2001, dentre muitos outros). Portanto, o "Kanban não é para todos" (SIPPER; BULFIN, 1997). Para MacCarthy e Fernandes (2000), o Kanban é um sistema adequado para sistemas de produção em massa e repetitivos.

A literatura a respeito do Kanban é bastante vasta. Algumas revisões encontradas na literatura são: Akturk e Erhun (1999); Price et al. (1994); Berkley (1992); Uzsoy e Martin-Vega (1990); e Redá (1987).

\subsection{Sistema CONWIP CNE}

O sistema CONWIP foi introduzido por Sperman et al. (1990). O estoque em processo é igual ao número de contenedores na linha; aliás, CONWIP = constant work in process. Após o último estágio, o conteúdo do contenedor vai para o estoque juntamente com o cartão (ordem) e o contenedor volta vazio e sem cartão para o primeiro estágio. Quando há o consumo de tal conteúdo, o cartão vai para a backlog list (lista de pedidos em carteira). Havendo contenedor disponível e cartão na backlog list, o operador começa a processar o primeiro cartão desta lista. O cartão, indicando várias instruções (o que produzir, em que quantidade, matéria-prima a ser

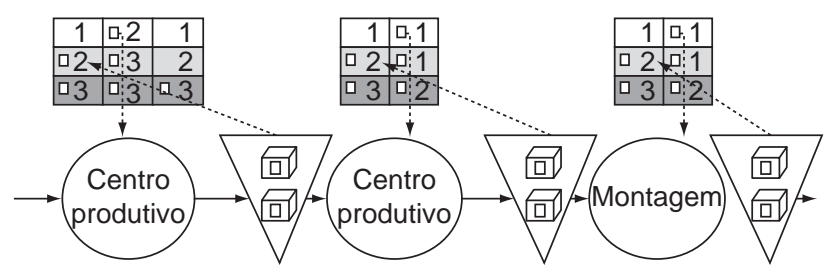

Figura 2. Funcionamento do Kanban CNE com apenas o cartão P. 
utilizada, em que estações executar as operações), segue com o contenedor já reabastecido com matéria-prima pela unidade produtiva até o último estágio. O que confere a este sistema a característica de puxar a produção é que quando o item estocado sai do estoque e vai para o cliente (interno ou externo), o cartão referente a este item vai para a última posição na fila de cartões; assim esse cartão (ordem que configura o fluxo de informação) vai numa direção e o fluxo de materiais caminha em direção oposta. Observe que na variante CNE nenhum estágio produtivo é programado.

Com relação à aplicabilidade do CONWIP CNE, temse que este sistema trabalha bem em linhas de produção com fluxo estável e uniforme (SIPPER; BULFIN, 1997). Este sistema pode ser utilizado em ambientes com uma variedade de produtos maior do que o Kanban CNE. Um método para a determinação do número de cartões CONWIP em uma linha de produção pode ser encontrado em Hopp e Spearman (1991).

\subsection{Sistema de estoque-base}

A referência clássica sobre este sistema é Clark e Scarf (1960). Este é o SCO mais difícil de classificar. Como a informação sobre o que, quanto e quando produzir ou comprar vem do departamento de PCP, ele é um sistema de fluxo programado; como a informação (ordem) vinda do PCP é empurrada em direção à próxima área de estocagem, ele é um sistema que empurra a produção. Resumidamente, o funcionamento deste sistema é o seguinte: são emitidas pelo departamento de PCP, no início do período, ordens de fabricação e compra para os diversos setores de produção. Os lotes são definidos a partir de quantidades consumidas no período anterior (ou previsão para o período futuro em função do programa mestre de produção - MPS) somados a uma quantidade em estoque que se deseja ter no final do período (estoque base que funciona como um estoque de segurança) menos a quantidade já disponível em estoque no início do período. Quando as ordens chegam nos departamentos, a produção é empurrada em direção ao próximo setor produtivo.

Com relação à aplicabilidade, de acordo com Burbidge (1988) o sistema de estoque-base é adequado em um ambiente onde não exista sazonalidade na demanda e exista um grande número de produtos (o que torna bastante difícil a previsão), mas por outro lado, o fluxo de materiais seja simples.

Alguns autores que tratam deste sistema são: Johansen (2005; 2001); Liberopoulos e Dallery (2002); Gullu (1998); Lee e Zipkin (1992). Alguns autores trazem comparações entre o sistema de estoque-base e outros sistemas, por exemplo: estoque-base e CONWIP (Duenyas e Patana-Anake, 1998); estoque-base, Kanban, combinação Kanban/CONWIP e MRP (PATERNINA-
ARBOLEDA; DAS, 2001). Já Dallery e Liberopoulos (2000) propõem combinar o sistema de estoque-base e o Kanban.

\subsection{Sistema PBC}

O funcionamento básico do PBC (period batch control) é o seguinte: partindo-se de um MPS definido para ciclos de igual tamanho, é feita a sua "explosão" para definir as quantidades a serem produzidas de cada item dentro do ciclo em questão. Após isso, atribuem-se tempos para as etapas do processo, incluindo expedição, montagem, fabricação de componentes e emissão de ordens/obtenção de materiais. Essa atribuição de tempos é repetida para todos os ciclos. O MPS pode ser elaborado a partir da carteira de pedidos ou da previsão de vendas. Uma importante vantagem de trabalhar com ciclos curtos é que o sistema se torna "[...] mais flexível e pode rapidamente seguir as alterações na demanda do mercado, com um mínimo investimento em estoque [...]" (BURBIDGE, 1975). Por outro lado, quando se define o ciclo como sendo, por exemplo, de uma semana em 3 etapas (períodos) de dois dias; portanto 6 dias úteis, assume-se que é possível executar as montagens em dois dias, produzir (ou receber) os componentes em dois dias, produzir (ou receber) as matérias-primas em dois dias.

Com relação à aplicabilidade do $\mathrm{PBC}$, tem-se que este sistema é adequado para sistemas de produção repetitivos e semi-repetitivos (MAcCARTHY; FERNANDES, 2000). Além disso, a implantação do PBC requer algumas condições (BURBIDGE, 1994): o tempo de processamento de todos os produtos deve ser menor que um período (portanto, itens com leadtimes grandes, que não podem ser reduzidos, não podem ser controlados pelo $\mathrm{PBC}$ ); o tempo de set up deve ser reduzido para que quando se desejar trabalhar com períodos mais curtos não haja prejuízo à capacidade da fábrica; os leadtimes de compras devem ser menores que um período (altos leadtimes de suprimentos inviabilizam o uso do PBC para controlar estes itens). Uma maneira de se tentar atenuar a primeira e a segunda limitação é a utilização de layout celular (BURBIDGE, 1975). Mais detalhes a respeito do sistema PBC são encontrados em diversos trabalhos, como por exemplo: Silva (2002); Zacarelli (1987); Burbidge (1975; 1988; 1994; 1996); Steele e Malhotra (1997); Zelenovic e Tesic (1988); Kaku e Krajewski (1995), sendo que estes quatro últimos trabalham bastante com a relação entre PBC e o layout celular. Vale destacar ainda: a) é o sistema que mais facilita a utilização de regras ou algoritmos de seqüenciamento de ordens de produção; e b) Benders e Riezebous (2002) consideram que o PBC é um clássico e não um sistema desatualizado.

Na Figura 3 o esquema lógico do PBC é aplicado a um ambiente produtivo típico da indústria calçadista.

Pela Figura 3, pode-se observar que: 


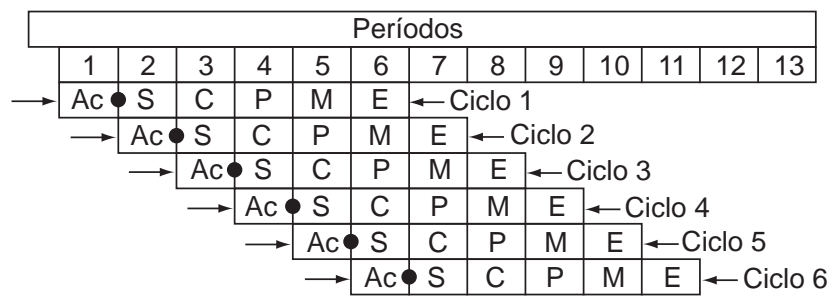

\begin{tabular}{|c|c|}
\hline Ac & Acúmulos de Pedidos \\
\hline$\bullet$ & Momento da elaboração da programação da produção \\
\hline S & Suprimentos (obtenção e separação dos materiais) \\
\hline C & Corte \\
\hline $\mathrm{P}$ & Pesponto \\
\hline M & Montagem (acabamento) \\
\hline E & $\begin{array}{l}\text { (Acabamento) expedição (envio para os clientes } \\
\text { dos produtos acabados) }\end{array}$ \\
\hline
\end{tabular}

Figura 3. Sistema de coordenação de ordens PBC aplicado a um ambiente produtivo típico da indústria calçadista.

a) cada ciclo é composto por 6 estágios produtivos (acúmulo de pedidos, suprimentos, corte, pesponto, montagem/acabamento e acabamento/expedição).

b) no período 6 , o processo produtivo estará:

- expedindo o que foi montado no período 5 (completando o ciclo 1);

- montando o que foi pespontado no período 5 (atividades do ciclo 2);

- pespontando o que foi cortado no período 5 (atividades do ciclo 2);

- cortando os materiais que foram separados no período 5 (atividades do ciclo 4);

- obtendo os materiais de acordo com os pedidos alocados ao período 5 (início do ciclo 5); e

- acumulando pedidos que serão programados para o próximo ciclo (neste caso sexto ciclo) ou para ciclos posteriores, caso a demanda atual (pedidos em carteira a alocar) exceda a capacidade de um ciclo.

\subsection{Sistema MRP}

O MRP é o SCO mais utilizado atualmente no mundo e a literatura sobre o MRP é extremamente vasta. Alguns dos assuntos tratados nesta literatura são: a) conceituação (ORLICKY, 1975; CORRÊA; GIANESI, 1996) e todo e qualquer livro de PCP escrito nos últimos 20 anos; b) parametrização do sistema (HAUTANIEMI; PIRTTIÄ, 1999; KIM; HOSNI, 1998; MOLINDER, 1997); c) medidas de performance (PLENERT, 1999); d) instabilidades no sistema (ENNS, 2002; HO; IRELAND, 1998; KADIPASAOGLU; SRIDHARAN, 1997); e) implementação (SUM et al., 1999; SUM et al., 1997); e f) estoque de segurança do sistema (GUIDE Jr.; SRIVAS-
TAVA, 2000; DELLAERT; JEUNET, 2005). Existem diversos artigos que relacionam dois ou mais aspectos citados acima. Por exemplo, o trabalho de Enns (1999) trata da relação entre parametrização e a performance do sistema; Enns (2002) trata da relação entre instabilidades no sistema e sua performance e o trabalho de Ho e Ho (1999) relaciona a questão da parametrização à instabilidade do sistema. Também revisões da literatura sobre o tema estão disponíveis, como por exemplo: Koh et al. (2002); Kumar e Meade (2002); Yeung et al. (1998); Murthy e Ma (1991) e Billington et al. (1983).

A grande vantagem dos sistemas MRP é a possibilidade de sua implantação em ambientes com grande variedade de produtos (sistemas não repetitivos) com estruturas complexas, ambientes estes não propícios à utilização da grande maioria dos SCO. Por outro lado, por ser um sistema de grande porte, requer grandes investimentos (maior que a grande maioria dos SCO), além de apresentar grande dificuldade no dimensionamento de leadtimes e não tratar de forma desejável a questão da programação no curto prazo, uma vez que é um sistema de capacidade infinita.

\subsection{Sistema OPT}

Para Sipper e Bulfin (1997), o OPT é o programador de gargalo (componente técnico) do conceito gerencial conhecido como teoria das restrições (TOC). Como é um sistema, por razões de sigilo comercial, repleto de segredos, ele não será aqui abordado, mas pode-se dizer que ele combina de uma forma não transparente a lógica do MRP, a teoria de scheduling e procedimentos avançados de programação de computadores.

Quanto à aplicabilidade, o OPT é adequado para sistemas semi-repetitivos(MACCARTHY; FERNANDES, 2000). As vantagens da utilização do OPT estão relacionadas a reduções de leadtime e estoques. As limitações estão relacionadas aos altos custos, dificuldades de utilização e análises do software, uma vez que o OPT é praticamente uma caixa preta. "[...] OPT é tudo menos transparente, ele é verdadeiramente difícil de entender [...]” (VOLLMAN, 1997). “[...] Deve-se pagar até 500 mil dólares por um sistema cuja operação é um mistério, na esperança de que ele funcione conforme propalado [...]" (MELETON, 1986).

\subsection{Sistema do controle MaxMin}

Como o mecanismo de controle do sistema MaxMin reage a variações tanto no suprimento quanto no consumo, a determinação do programa de necessidades pode ser feita de uma forma menos precisa que a explosão do MPS. Após isso, deve-se definir um estoque de segurança para cada item. Isso é feito para que atrasos temporários no fornecimento ou aumentos de consumo não provoquem falta de estoque. Devem-se fixar os limites de 
estoques. A variação normal de estoque ocorrerá entre o nível do estoque de segurança e (esse nível + lote de entrega). Variações significativamente fora desses limites merecem atenção de modo a se prevenir contra falta ou excesso de estoque. Os limites de controle, mínimo e máximo, não necessariamente devem ser definidos como sendo (estoque de segurança) e o (estoque de segurança + lote de entrega), inclusive esses limites podem variar, por exemplo, no calor ser um e no frio outro, refletindo certa sazonalidade do produto. Então, devem-se emitir ordens na forma de programas de necessidades. Uma requisição de compra típica do sistema MaxMin (BURBIDGE, 1988) mostra que o programa é enviado ao fornecedor como um pedido global, e ele então passa a fazer as entregas de acordo com o programa, não sendo acompanhado (e então alterado) de nenhum modo, a menos que o estoque saia dos limites de controle. Finalmente devemse manter registros de estoque e usá-los para controle. Por este funcionamento se vê que o sistema MaxMin é um sistema híbrido, pois apesar deste sistema ser programado via MPS (PCP central), são os registros de estoque que puxam a produção. Geralmente, no sistema MaxMin as entregas devem ser feitas a intervalos regulares para cobrir uma necessidade fixa por período.

Referente à aplicabilidade, de acordo com Burbidge (1988) este sistema é adequado para controlar o fornecimento de componentes e materiais de demanda independente, comprados com valor unitário baixo e demanda regular, e de fácil previsibilidade.

\subsection{Sistema CONWIP H (híbrido)}

Este sistema é bastante parecido com o CONWIP CNE descrito anteriormente. A diferença é que a lista de cartões é gerada a partir da explosão do programa mestre de produção (MPS), vindo, portanto, do departamento de PCP e não pela regra FIFO; (Figura 4). Como já explicitado anteriormente, esta lista é chamada por alguns autores (SIPPER; BULFIN, 1997) por exemplo, de lista de pedidos em carteira (backlog list). Desta forma neste sistema as decisões são originadas do PCP a partir da explosão do MPS, ao mesmo tempo em que a informação de que o nível de WIP abaixou em um contenedor vem em direção oposta ao fluxo de materiais. Disso decorre a característica híbrida deste sistema. Um algoritmo para

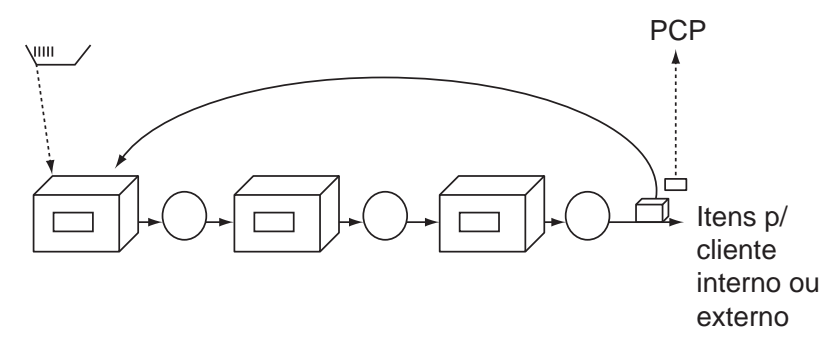

Figura 4. Funcionamento do sistema CONWIP H. a geração do MPS em um ambiente CONWIP é encontrado em Herer e Masin (1997).

O CONWIP H aplica-se a sistemas repetitivos, permitindo uma variedade de coisas diferentes (distinção) um pouco maior (ou uma variedade de coisas semelhantes - diversidade - maior) do que o Kanban $\mathrm{H}$ e maior que o CONWIP CNE, e este sistema pode lidar melhor com situações nas quais as demandas são flutuantes e os tempos de set-ups não tão pequenos (SIPPER; BULFIN, 1997).

A literatura sobre o CONWIP (tanto CNE quanto o $\mathrm{H}$ ) é relativamente vasta. Dentro desta literatura, merecem destaque a utilização do CONWIP para a gestão da cadeia de suprimentos (OVALLE; MARQUEZ, 2003) e estudos que trazem comparações entre a performance do CONWIP e a de outros SCO, como por exemplo: CONWIP e Kanban (TAKAHASHI; MYRESHKA, 2005; TAKAHASHI; NAKAMURA, 2002); CONWIP e MRP (RODERICK et al., 1994); CONWIP, Kanban e MRP (HUANG et al., 1998); CONWIP, Kanban, estoquebase e combinação Kanban-CONWIP (BONVIK et al., 1997); CONWIP e DBR (KOH; BULFIN, 2004); dentre muitos outros.

De acordo com Framinan et al. (2003), os quais apresentam uma revisão da literatura sobre o CONWIP, muitos sistemas propostos na literatura têm características idênticas ou bastante similares ao CONWIP. É o caso de sistemas como: "controle de carga de trabalho" (BERTRAND, 1983); "linha flexível global" (SO, 1990); "Kanban de estágio único" (SPEARMAN, 1992; DI MASCOLO et al., 1996; KARAESMEN; DALLERY, 2000; TARDIFF; MAASEIDVAAG, 2001). Geralmente o CONWIP considerado é o híbrido, uma vez que o primeiro estágio produtivo é programado; caso isto não ocorra, o sistema passa a ser do tipo CNE (controlado pelo nível de estoque).

\subsection{Sistema Kanban H (híbrido)}

Aqui denominam-se Kanban $\mathrm{H}$ as variações do Kanban que têm características híbridas, ou seja, sistemas que apesar de puxar a produção têm o último estágio programado via um MPS (geralmente denominado Programa de Montagem) desenvolvido por um PCP central. Nestas variações estão: a) Kanban $\mathrm{H}$ de duplo cartão; b) Kanban H somente com cartão de ordem de produção (é a variante do sistema Kanban mais utilizada em fábricas no Brasil e está ilustrada na Figura 5); e c) Kanban H somente com cartão de requisição. Os casos a e b funcionam de forma semelhante aos Kanbans CNE de duplo cartão e somente com cartão de produção vistos anteriormente; a diferença é que o último estágio é programado.

No caso do sistema Kanban com apenas o cartão de requisição, a lógica é a seguinte: quando um centro de trabalho requer mais componentes para serem 


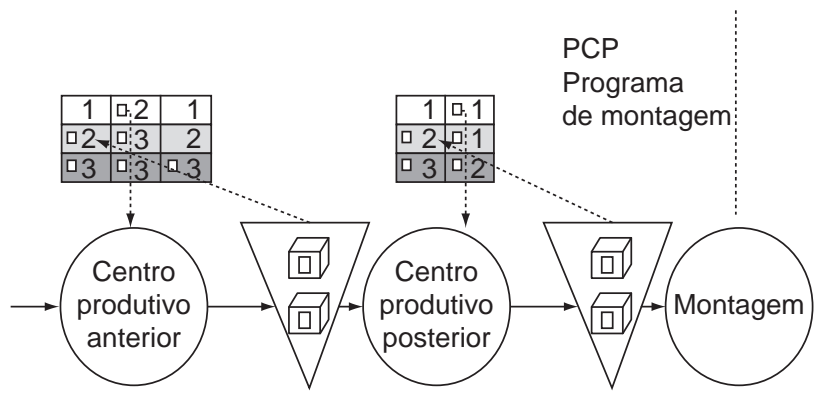

Figura 5. Funcionamento Kanban $\mathrm{H}$ com apenas o cartão de ordem de produção.

processados, ele coleta um contenedor cheio direto da armazenagem do estágio anterior. Após a produção, o contenedor vazio é enviado ao estágio de produção anterior e este representa o sinal para a produção neste estágio ou, o estágio anterior também é programado. Já o cartão de requisição vai para uma caixa de espera. A saída deste cartão da caixa de espera, de volta ao ponto de estocagem, representa a autorização para a movimentação de mais um contenedor cheio.

Além destas variações do próprio Kanban existem na literatura outros sistemas que se originaram do Kanban. Um destes sistemas é o chamado "Kanban genérico" proposto originalmente por Tayur (1992) e também mostrado em Chang e Yih (1994). Este sistema pode ser visto como uma série de segmentos com controle CONWIP em cada um dos segmentos. O trabalhoé puxado entre cada segmento e empurrado dentro do segmento. Se o sistema como um todo puder ser considerado como somente um elemento, então o Kanban genérico se transforma no CONWIP; caso cada segmento seja composto de somente uma máquina, então o Kanban genérico se transforma no Kanban puro. Uma outra variação bastante conhecida do Kanban é o chamado sistema do bloqueio mínimo "minimal blocking", proposto por So e Pinault (1988). Na verdade este sistema é um pouco diferente da lógica de um típico sistema puxado, porém neste sistema é mais fácil as máquinas se recuperarem de falhas e manterem os gargalos trabalhando, mesmo se ocorreram falhas em estações de trabalho anteriores (SO; PINAULT, 1988). Para mais informações a respeito de mais variantes do Kanban, verificar Di Mascolo et al. (1991) e Berkley (1992).

Em todos estes casos, para o sistema ser considerado híbrido, há a necessidade do último estágio ser programado e caso isto não ocorra o sistema passa a ser do tipo controlado pelo nível de estoque (CNE).

\subsection{Sistema DBR (drum = tambor; buffer = pulmão; rope = corda)}

Assim como o OPT, também o DBR é um sistema que regula o fluxo de materiais baseado na Teoria das Restrições e foi criado por Goldratt.
No livro A Meta, Goldratt e Cox (2003) fazem a seguinte analogia entre uma excursão de escoteiros em fila indiana e o fluxo de materiais em um processo de produção. Na marcha, se cada um seguir seu passo (taxa de produção), a distância entre o primeiro e o último aumentará, já que os mais rápidos logo ficarão na frente (o que corresponde a aumentar o estoque em processo). Só após o último chegar ao destino, todos os escoteiros terão chegado ao destino. O tempo para completar a jornada (o makespan $=$ tempo para concluir todas as ordens de produção) é dado pelo escoteiro mais lento, que corresponde a um gargalo de produção. Para manter a tropa junto (ou seja, manter pequeno o estoque em processo) pode-se amarrar uma corda em cada um deles (corresponde à linha de montagem cadenciada mecanicamente) e fornecer uma cadência à tropa por meio de um tambor. Quando bate o tambor, todos avançam até o escoteiro que está a sua frente. Se o escoteiro mais lento não conseguir manter o ritmo ditado pelo primeiro escoteiro (aquele que está com o tambor), o mais lento e os que estão atrás dele ficarão separados do restante da tropa. Portanto, o escoteiro da frente é obrigado a marchar ao passo do escoteiro mais lento por causa da corda. Deve haver uma folga no comprimento da corda, de modo que os escoteiros (afora o primeiro e o mais lento) possam andar mais rápido ou mais lento sem interferir no passo do mais lento. Essa é a abordagem DBR.

$\mathrm{Na}$ situação de manufatura o tambor corresponde a cada recurso no qual entra matéria-prima; um pulmão deve ser colocado antes do gargalo e antes do CCR (o recurso que não for convenientemente programado, o fluxo não conseguirá atender a demanda) e a corda informa ao tambor se o pulmão está ou não cheio; se estiver, o tambor não iniciará nova operação (Figura 6).

Por este funcionamento se vê que este sistema é um sistema híbrido, uma vez que o estoque (pulmão) puxa a produção por meio da corda (feedback de informação), porém o CCR é programado via o PCP central. Também pelo funcionamento se vê que a aplicabilidade do DBR é em ambientes com linhas ou células com padrão de fluxo flow-shop, ou seja, sistemas de produção repetitivos.

Alguns trabalhos que tratam do sistema DBR são: Chakravorty e Atwater (2005); Corbett e Csillag (2001); Sivasubramanian et al. (2000); dentre outros. Até mesmo a ampliação da lógica DBR para a cadeia de suprimentos é estudada (WALKER, 2002).

Um sistema bastante similar ao DBR, apenas com pequenas diferenças (e que também tem características do CONWIP, segundo FRAMINAN et al., 2003), é o chamado sistema "starvation avoidance". Este sistema se comporta igual ao DBR; a diferença principal é que no cálculo da carga de trabalho, antes do gargalo, este sistema inclui um tempo esperado de reparo do gargalo como parte da carga de trabalho. Este sistema é mostrado 


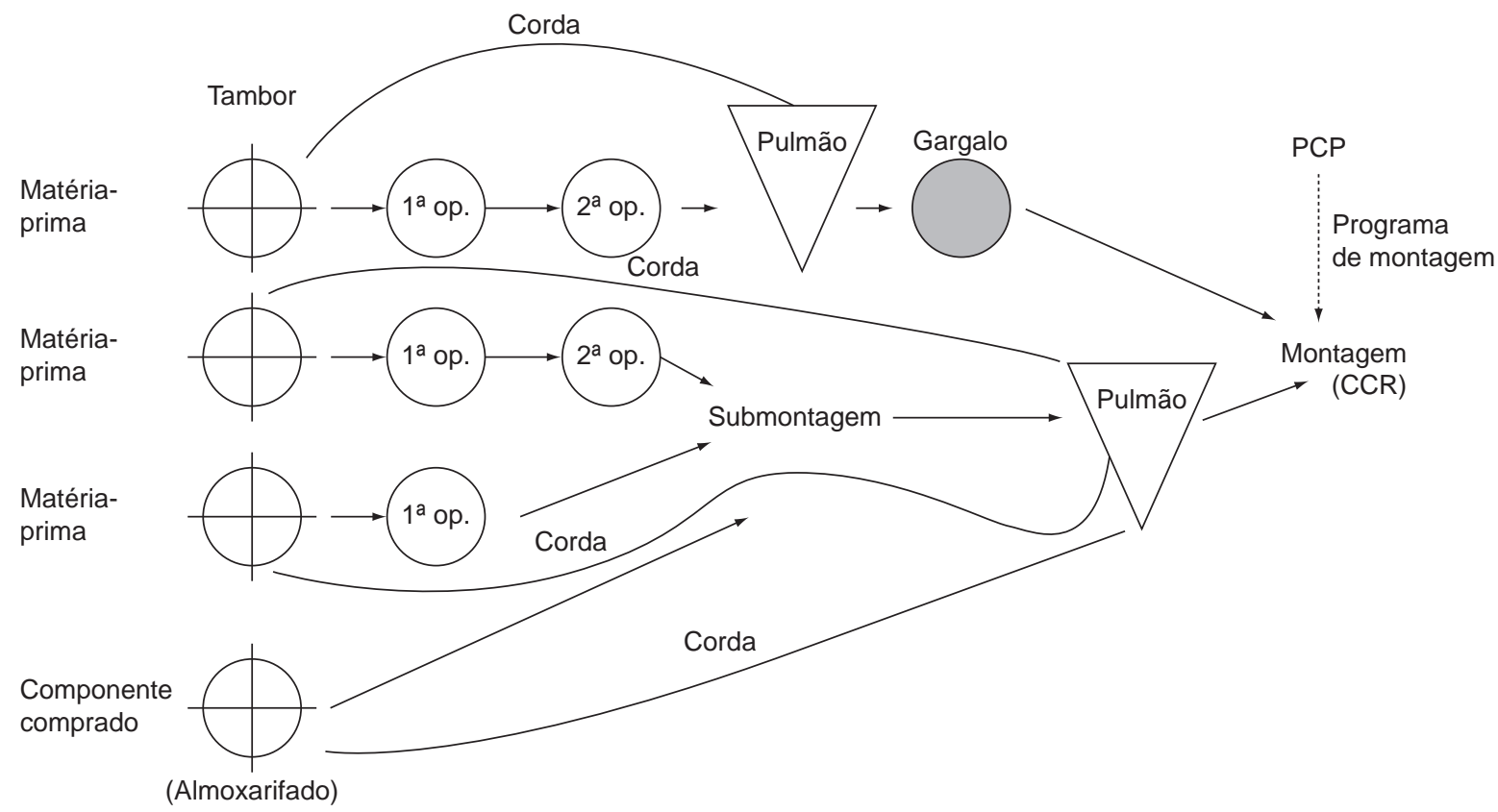

Figura 6. Exemplo de sistema DBR. Fonte: Baseado em Narasimhan et al. (1995).

em Glassey e Resende (1988a,b). Uma extensão do "starvation avoidance" é o chamado sistema QMRP (queue management release policy). Neste sistema o tempo ocioso dos recursos gargalos é previsto com base em uma probabilidade de que o recurso fique inativo. Este sistema é mostrado em Leachman et al. (1988).

\subsection{Sistema DEWIP (descentralized work in process)}

O sistema DEWIP foi proposto inicialmente por Lödding (2001). O sistema DEWIP é direcionado a ambientes job shop com grande variedade de itens (sistemas não repetitivos) e fluxo de material complexo (LODDING et al., 2003). O DEWIP objetiva atingir leadtimes curtos e confiáveis. A variável primária de controle no sistema DEWIP é o estoque em processo (WIP), o qual é estabelecido por meio de ciclos de controle entre as próprias estações de trabalho. Isto caracteriza este sistema como um sistema de controle descentralizado.

Seis regras básicas explicam melhor como o DEWIP trabalha:

a) Antes de iniciar um trabalho o operário pede permissão para o centro de trabalho posterior (à frente). Isto é chamado na literatura de "go-ahead request";

b) O operário à jusante decide dar ou não a autorização de produção para o centro de trabalho anterior baseado em um limite de WIP permitido. O cálculo deste WIP permitido é feito somando-se o WIP do próprio centro de trabalho (chamado WIP direto) e os WIP dos centros de trabalho antecedentes a este, levando-se em conta as autorizações de produção já dadas (chamado WIP indireto);

c) Se existir uma autorização para iniciar o trabalho o operário inicia a produção; caso contrário este centro de trabalho pede permissão para outros centros de trabalho à jusante (uma vez que o ambiente é do tipo job shop);

d) Após processar uma ordem o trabalhador subtrai o conteúdo de trabalho do WIP do seu centro de trabalho. Se isto faz com que o nível de WIP caia abaixo do nível limite, ele fornece autorizações para produção nos centros de trabalho anteriores;

e) Um centro de trabalho sempre autoriza uma produção (independentemente do nível de estoque) caso o centro de trabalho requisitante seja um recurso crítico; e

f) Todas as ordens de produção são programadas por um PCP central. Portanto, esta programação define a prioridade de produção, e o controle do WIP define quando produzir.

Analisando as características de funcionamento deste sistema, notamos que este sistema apesar de puxar a produção e ter características de controle descentralizado, depende de uma programação de um PCP central como nota-se na regra (f); portanto, ele é um sistema híbrido.

\subsection{Sistema LOOR (load oriented order release)}

O sistema LOOR foi desenvolvido por Bechte (1980). Este sistema é também conhecido por sua sigla em 
alemão (BORA). No sistema LOOR uma carga limite é estabelecida para cada centro de trabalho. Uma tarefa é liberada somente se a carga projetada para cada centro de trabalho em um horizonte de tempo (por exemplo, uma semana) for menor que esta carga limite. A carga projetada de um centro de trabalho é formada pelas tarefas sendo processadas no centro de trabalho somadas às cargas de trabalho que estão chegando de outros centros para serem processadas, devidamente descontadas por um fator de desconto probabilístico.

Na verdade, no sistema LOOR, o planejamento é realizado em três níveis:

a) Entrada das ordens e análise de capacidade de médio prazo: as ordens de produção (contendo quantidades e datas devidas) vão para um estoque de ordens (geralmente um banco de dados). Conhecendo-se os leadtimes corretos de todas as operações é realizada uma programação para trás e as cargas resultantes nos centros de trabalho são estabelecidas. Então as datas devidas são checadas e ajustadas se necessário. O horizonte de planejamento desta fase deve ser pelo menos igual ao maior leadtime acumulado dos itens do sistema (12 semanas são normalmente suficientes);

b) Liberação das ordens e análise de capacidade de curto prazo: acontece periodicamente (por exemplo, todo dia ou toda semana) para todas as ordens planejadas que devem se iniciar num futuro próximo. A técnica da liberação das ordens seleciona dentre as ordens planejadas as que podem ser trabalhadas, de acordo com um limite de carga. Isto limita o estoque em processo resultando em leadtimes e níveis de estoque controlados. O limite de carga permitido para um centro de trabalho é calculado como sendo [(período de planejamento + Leadtime planejado)/ (período de planejamento)] x 100. Para se aplicar a técnica do limite de carga para os centros de trabalho à jusante, o sistema LOOR propõe que este cálculo seja feito por meio de uma abordagem estatística, a qual se baseia na probabilidade da carga chegar ao centro de trabalho; e

c) Seqüenciamento da produção: nesta fase ocorre a programação das ordens de produção que concorrem em um mesmo centro de trabalho. Esta programação considera uma prioridade com relação às datas programadas. Isto vai manter a acurácia nos leadtimes planejados

De acordo com Graves et al. (1995), o LOOR é um sistema adequado para ambientes job shop. Também Lödding et al. (2003) caracterizam o LOOR como um sistema voltado a ambientes com alta variedade de itens e alta complexidade do fluxo de materiais. Ainda de acordo com estes autores, o LOOR é um sistema que pode ser caracterizado como tendo como variável de controle primária o WIP (estoque em processo) e centralizado (uma vez que os níveis de WIP são determinados em um nível de controle centralizado e não pelas próprias estações de trabalho). O funcionamento do LOOR caracteriza este sistema como um sistema de fluxo programado que empurra produção, porém a liberação ocorre baseada nos níveis de carga (WIP); portanto, essas duas características o tornam um sistema híbrido, mas não seria um erro considerá-lo um sistema de fluxo programado já que a programação tem um papel absolutamente vital.

Algumas referências importantes sobre o LOOR em língua inglesa são: Bechte (1988); Wiendahl et al. (1992); Zapfel e Missbauer (1993); Breithaupt et al. (2002). Além destes, Knolmayer (1991) fornece uma vasta revisão da literatura sobre o sistema LOOR, porém a maioria em língua alemã.

\subsection{Sistema POLCA (paired-cell overlapping loops of cards with authorization)}

O sistema POLCA foi criado por Suri (1998). Este sistema é parte de uma estratégia maior proposta pelo autor denominada quick response manufacturing (QRM). Esta estratégia visa a obtenção da vantagem competitiva por meio da redução dos leadtimes. Portanto dentro desta estratégia o PCP tem papel fundamental. Antes da implementação do POLCA, ainda dentro da estratégia do QRM a empresa deve reorganizar sua produção em uma estrutura celular.

O sistema POLCA apresenta basicamente quatro características:

a) autorização de liberação por meio de um sistema denominado HL/MRP (higher level MRP). O sistema HL/MRP é semelhante ao sistema MRP convencional com duas diferenças: a) o HL/MRP é baseado em uma estrutura de produtos simplificada, utilizando os leadtimes das células ao invés dos leadtimes individuais dos centros de trabalho dentro de cada célula; e b) as datas planejadas pelo HL/MRP são apenas datas nas quais as tarefas podem ser iniciadas (por isso são chamadas datas de autorização e não de liberação como no MRP convencional), sendo que seu início concreto na produção se dá somente mediante esta autorização, e também mediante a disponibilidade do cartão POLCA na célula que vai iniciar o trabalho;

b) método de controle de material baseado em um cartão (denominado cartão POLCA). Estes cartões são utilizados para comunicação e controle entre as células; dentro das células pode ser usado outro sistema de controle, como por exemplo, o Kanban;

c) Os cartões POLCA, ao invés de se referirem especificamente a um produto, se referem a um par de células escolhidas da seguinte forma: se o roteiro de uma ordem qualquer sair de uma célula A para uma 
célula $\mathrm{B}$, então é criado um cartão POLCA A/B e assim por diante para as outras etapas do processamento. Este procedimento de trabalhar com as células em pares faz com que o cartão POLCA garanta que uma célula somente irá trabalhar em uma tarefa para a qual a célula de destino tem capacidade disponível; e

d) O cartão POLCA para cada par de células permanece com a tarefa durante toda sua jornada (incluindo processamento) através das duas células e depois retorna para a primeira célula quando é finalizado o processamento na segunda célula. Neste momento, a primeira célula pode iniciar outra tarefa.

Resumidamente, o funcionamento do POLCA é o seguinte: quando uma empresa recebe uma ordem de cliente o sistema HL/MRP usa os leadtimes planejados de cada célula para determinar quando cada célula no roteiro do produto pode iniciar o processamento da tarefa. Estas datas de autorização serão seguidas somente se um cartão POLCA estiver disponível na célula que inicia a operação. A Figura 7 ilustra o funcionamento do sistema POLCA.

De acordo com Suri (1998), o sistema POLCA é um híbrido entre os sistemas de puxar e empurrar a produção, uma vez que combina as melhores características dos sistemas baseados em cartão que puxam a produção com os sistemas que empurram a produção, por meio da programação de um PCP central. Isto faz com que classifiquemos este sistema como híbrido.

Com relação ao ambiente de produção adequado ao POLCA, Suri (1998) cita que este sistema é direcionado

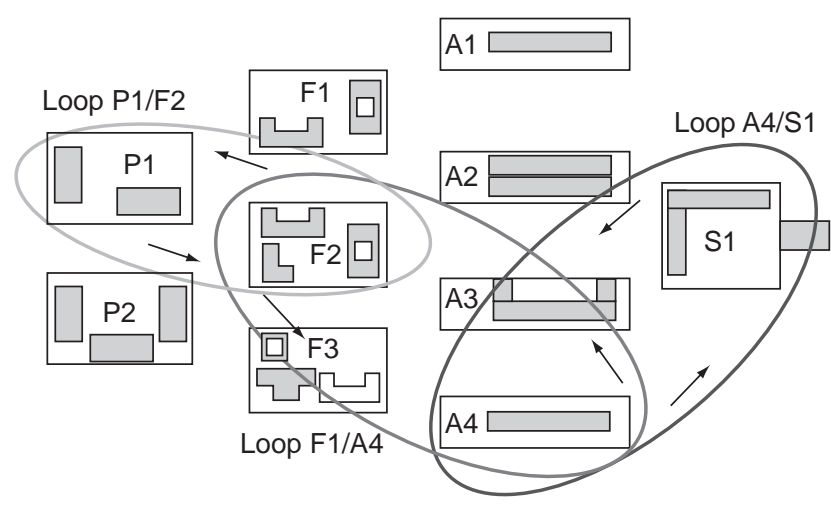

Figura 7. Ilustração do fluxo de cartões no sistema POLCA. Fonte: Suri (1998). a ambientes com alta variedade de produtos. Também Lödding et al. (2003) caracterizam o POLCA como um sistema voltado a ambientes com alta variedade de itens e alta complexidade do fluxo de materiais. Ainda de acordo com estes autores, o POLCA é um sistema que pode ser caracterizado como descentralizado e com variável primária de controle - o WIP.

\section{Conclusões}

O presente trabalho propôs inicialmente uma nova nomenclatura para os ordering systems, Sistemas de coordenação de ordens (SCO). Esta nova nomenclatura mostra melhor o que estes sistemas realmente fazem: programam ou organizam/explodem as necessidades em termos de componentes e materiais e/ou controlam a emissão/liberação das ordens de produção e compra e/ou programam/sequenciam as tarefas nas máquinas. Além disso, este trabalho também realiza uma revisão e classificação da literatura a respeito dos principais SCO atualmente encontrados. Para cada um destes sistemas é mostrada a lógica de funcionamento e sua aplicabilidade, bem como referências importantes para estudos focados em um sistema em particular.

As principais contribuições do presente trabalho são: a) auxilia na escolha prática dos SCO por meio de um melhor entendimento das características de funcionamento e aplicabilidade dos sistemas; b) fornece uma referência importante para pesquisas futuras sobre os SCO, uma vez que é uma visão geral, pragmática e comparativa a respeito dos $\mathrm{SCO}$; e c) a classificação e terminologia propostas auxiliam a entender melhor a natureza dos diversos SCOs. Vale destacar que todos os sistemas recentes são sistemas híbridos, e que o SCO adotado influencia diretamente em como o MPS deve ser gerado e até mesmo se ele precisa ser gerado.

Para futuros trabalhos sugere-se: aprofundar a relação entre os SCO e a organização da produção (algo iniciado na Figura 1 deste artigo), a relação entre os $\mathrm{SCO}$ e a teoria de scheduling (já se adiantou neste artigo, algo que pode ser explorado em detalhes em futuros trabalhos, que existe um casamento perfeito entre o sistema PBC e a teoria estática de seqüenciamento) e a discussão sobre o desempenho desses SCO em situações de baixa, média e alta complexidade, sendo que para isso, a simulação é uma ferramenta importantíssima. 


\title{
Systems for coordinating orders: review, classification, operationality and applicability
}

\begin{abstract}
Ordering systems are the focus of this work. Ordering systems are information systems which schedule or organize requirements in terms of components and materials and/or control the production and purchase orders emission/release being able to restrain or not rules of sequencing orders. Within this context, this paper intends: to present a new nomenclature for ordering systems, Systems for Coordinating purchase and production Orders (SCO); to present a typology that is able to classify all the systems in a rational way; to discuss some systems which have high potential for success applications and that are relatively unknown in Brazil and, to highlight a theme which is highly important to Production Planning and Control (PPC) in the scientific Brazilian literature.
\end{abstract}

Keywords: Production control. Ordering systems. Systems for coordinating purchase and production orders. Review. Classification.

\section{Referências bibliográficas}

AKTURK, M. S.; ERHUM, F. Overview of design and operational issues of kanban systems. International Journal of Production Research, v. 37, n. 17, p. 3859-3881, 1999.

BECHTE, W. Steuerung der Durchlaufzeit durch belastungsorientierte Auftragsfreigabe bei Werkstattfertigung. (Dissertation) - Universitat Hannover 1980. Fortschrittsberichte VDI-Z, Reihe 3, Nr. 70, 1980.

Theory and practice of load-oriented manufacturing control. International Journal of Production Research, v. 26, n. 3, p. 375-395, 1988.

BENDERS, J.; RIEZEBOUS, J. Period Batch Control: Classic, not outdated. Production Planning and Control, v. 13, n. 6, p. 497-506, 2002.

BERGAMASCHI, D. et al. Order review and release strategies in a job shop environment: a review and a classification. International Journal of Production Research, v. 35, n. 2, p. 399-420, 1997.

BERKLEY, B. J. A review of the Kanban production control literature. Production and Operations Management, v. 1, p. 393-411, 1992.

BERTRAND, J. K. M. The use of Workload information to control job lateness in controlled and uncontrolled release production systems. International Journal of Operations Management, v. 3, n. 2, p. 79-92, 1983.

BILLINGTON, P.; McCLAIN, J. O.; THOMAS, L. J. Mathematical programming approaches to capacity - constrained MRP systems - review, formulation and problem reduction. Management Science, v. 39, n. 10, p. 1126-1141, 1983.

BONNEY, M. C. et al. Are push and pull systems really so different? International Journal of Production Economics. v. 59 , n. 1 , p. $53-64,1999$.

BONVIK, A. M.; COUCH, C. E.; GERSHWIN, S. B. A comparison of production-line control mechanisms. International Journal of Production Research. v. 35, n. 3, p. 789-804, 1997.

BOSE, G. J.; RAO, A. Implementing JIT with MRPII creates hybrid manufacturing environment. Industrial Engineering. v. 20, n. 9, p. 49-53, 1988.

BREITHAUPT, J.; LAND, M.; NYHUIS, P. The workload control concept - Theory and practical extensions of load-oriented order release. Production Planning and Control. v. 13, n. 7, p. 625-638, oct-nov 2002.

BURBIDGE, J. L. The Introduction of Group Technology. Heinemann London, 1975.

Planejamento e Controle da Produção. São Paulo: Ed. Atlas, 1988.

. Production Control: a universal conceptual framework. Production Planning and Control, v. 1, n. 1, p. 3-16, 1990.

The use of period batch control (PBC) in the implosive industries. Production Planning and Control, v. 5, n. 1, p. 97102, 1994.

Period Batch Control. Oxford (England): Clarendon Press, 1996.

CHAKRAVORTY, S. S.; ATWATER, J. B. The impact of free goods on the performance of drum-buffer-rope scheduling systems. International Journal of Production Economics. v. 95, n. 3, p. 347-357, 2005.

CHANG, M.; YIH, Y. Generic Kanban Systems for dynamic environments. International Journal of Production Research. v. 32, n. 4, p. 889-902, 1994.

CHIANG, C. Optimal replenishment for a periodic review inventory system with two supply modes. Journal of the Operational Research, v. 149, n.1, p. 229-244, 2003.

CLARK, A. J.; SCARF, H. Optimal policies for the multiechelon inventory problem. Management Science, v. 4, n. 4, p. 475-490, 1960.

CORBETT, T.; CSILlAG, J. M. Analyses of the effect of seven drum-buffer-rope implementations. Production and Inventory Management Journal, v. 42, n. 3-4, p. 17-23, 2001.

CORRÊA, H. L.; GIANESI, I. G. N. Just in Time, MRP II e OPT - Um enfoque estratégico. 2. ed, Ed. Atlas, 1996.

CORRÊA, H. L.; GIANESI, I. G. N.; CAON, M. Planejamento, Programação e Controle da produção. 4 ed. São Paulo: Editora Atlas, 2001.

DALLERY, Y.; LIBEROPOULOS, G. Extended Kanban control system - combining Kanban and base stock. IIE Transactions, v. 32, n. 4, p. 369-386, 2000. 
DELLAERT, N.; JEUNET, J. Na alternative to safety stock policies for multi-level rolling schedule MRP problems. Supply Chain Management and Advanced Planning, v. 163, n. 3, p. 751-768, 2005.

DI MASCOLO, M.; FREIN, M.; DALLERY, Y.: An analytical method for performance evaluation of Kanban controlled production systems. Operations Research, v. 44, n. 1, p. 50-64, 1996.

DI MASCOLO, M. et al. A unified modeling of Kanban systems using petri nets. International Journal of Flexible Manufacturing Systems, v. 3, p. 275-307, 1991.

DUENYAS, I.; PATANA-ANAKE, P. Base stock control for singleproduct tandem make-to-stock systems. IIE Transactions, v. 30, n. 1, p. 31-39, 1998.

DURAN, A.; GUTIERREZ, G.; ZEQUEIRA, R. I. A continuous review inventory model with order expediting. International Journal of Production Economics, v. 87, n. 2, p. 157-169, 2004.

ENNS, S. T. The effect of batch size selection on MRP performance. Computers \& Industrial Engineering, v. 37, n. 1-2, p.15-19, 1999.

ENNS, S. T. MRP performance effects due to forecast bias and demand uncertainty. European Journal of Operational Research, v. 138, n. 1, p.87-102, 2002.

FERNANDES, F. C. F. Concepção de um Sistema de Controle da Produção para a manufatura celular. Tese (Doutorado), Escola se Engenharia de São Carlos. São Carlos - SP, 1991.

FRAMINAN, J. M.; GONZÁLEZ, P. L.; RUIZ-USANO, R. The CONWIP production control system - review and research issues. Production Planning \& Control, v. 14, n. 3, p. 255-265, 2003.

GAVIRNENI, S. Periodic review inventory control with fluctuating purchasing costs. Operations Research Letters, v. 32, n. 4, p. 374-379, 2004.

GELDERS, L. F.; WASSENHOVE, L. N. Capacity Planning in MRP, JIT and OPT - a critique. Engineering Costs and Production Economics, v. 9, n. 1-3, p. 201-209, 1985.

GHALEBSAZ-JEDDI, B.; SHULTES, B.; HAJI, R. A multiproduct continuous review inventory with stochastic demand, backorders, and a budget constraint. European Journal of Operational Research, v. 158, n. 2, p. 456-469, 2004.

GLASSEY, C. R.; RESENDE, M. G. C. A closed-loop job release control for VLSI circuit management. IEEE Transactions on Semiconductor Manufacturing, v. 1, n. 1, p. 36-46, 1988a. scheduling rule for job shop release in semiconductor fabrication. Operations Research Letters, v. 7, n. 5, p. 213217, 1988b.

GOLDRATT, E.; COX, J. A Meta, 2. ed., Nobel, 2003.

GOOD, I. J. Categorisation of classification. In: Mathematics and Computer Science in Medicine and Biology, London: HMSO, 1965, p. 115-128.

GRAVES, R. J.; KONOPKA, J. M.; MILNE, R. J. Literature review of material flow control mechanisms. Production Planning \& Control, v. 6, n. 5, p. 395-403, 1995.

GUIDE JR; V. D. R.; SRIVASTAVA, R. A review of techniques for buffering against uncertainty with MRP systems. Production Planning \& Control, v. 11, n. 3, p. 223-233, 2000.

GULLU, R. Base Stock policies for production/inventory problems with uncertain capacity levels. European Journal of Operational Research, v. 105, n. 1, p. 43-51, 1998.

HAUTANIEMI, P.; PIRTTILÄ, T. The choice of replenishment policies in an MRP environment. International Journal of Production Economics, v. 59, n. 1, p. 85-92, 1999.
HERER, Y.T.; MASIN, M. Mathematical programming formulation of CONWIP based production lines; and relationship to MRP. International Journal of Production Research, v. 35, n. 4, p. 1067-1076, 1997.

HO, C. J.; HO, S. J. K. Evaluating the effectiveness of using lotsizing rules to cope with MRP system nervousness. Production Planning and Control, v. 10, n. 2, p.150-161, 1999.

HO, C. J.; IRELAND, T. C. Correlating MRP system nervousness with forecast errors. International Journal of Production Research, v. 36, n. 8, p. 2285-2299, 1998.

HOPP, W. J.; SPEARMAN, M. L. Factory Physics. Irwin, 1996. . Throughput of a Constant Work in Process Manufacturing Line Subject to Failures. International Journal of Production Research, v. 29, n. 3, p. 635-655, 1991.

HUANG, M.; WANG, D.; IP, W. H. Simulation and comparative study of the CONWIP, Kanban and MRP production control systems in a cold rolling plant. Production Planning \& Control, v. 9, n. 8, p. 803-812, 1998.

JACOBS, F. R.; WHYBARK, D. C. A comparison of reorder point and material requirements planning inventory control logic. Decision Sciences, v. 23, n. 2, p. 332-342, 1992.

JOHANSEN, S. G. Pure and modified base stock policies for the lost sales inventory system with negligible set-up costs and constant leadtimes. International Journal of Production Economics, v. 71, n. 1-3, p. 391-399, 2001.

Base-stock policies for the lost sales inventory system with Poisson demand and Erlangian leadtimes. International Journal of Production Economics, v. 93-94, special issue, p. 429-437, 2005.

JONSSON, P.; MATTSSON, S. The selection and application of material planning methods. Production Planning and Control, v. 13, n. 5, p. 438-450, 2002.

. The implications of fit between planning environments and manufacturing planning and control methods. International Journal of Operations and Production Management, v. 23, n. 8, p. 872-900, 2003.

KADIPASAOGLU, S. N.; SRIDHARAN, S. V. Measurement of instability in multi-level MRP systems. International Journal of Production Research, v. 35, n. 3, p. 713-737, 1997.

KAKU, B. K.; KRAJEWSKI, L. J. Period Batch Control in group technology. International Journal of Production Research, v. 33, n. 1, p. 79-99, 1995

KARAESMEN, F.; DALLERY, Y. A performance comparison of pull type control mechanisms for multi-stage manufacturing. International Journal of Production Economics, v. 68, n. 1, pp. 59-71, 2000.

KIM, H. J.; HOSNI, Y. A. Manufacturing lot-sizing under MRP II environment: an improved analytical model \& a heuristic procedure. Computers \& Industrial Engineering, v. 35, n. 3-4, p. 423-426, 1998.

KNOLMAYER, G. A widely acclaimed method of load-oriented job release and its conceptual deficiencies. In: G. FANDEL; G. ZAPFEL (eds). Modern Production Concepts, Berlin: Springer-Verlag, 1991, p. 219-236.

KOH, R. P.; BULFIN, R. L. Comparison of DBR with CONWIP in an unbalanced production line with three stations. International Journal of Production Research, v. 42, n. 2, p. 391-404, 2004.

KOH, S. C. L.; SAAD, S. M.; JONES, M. H. Uncertainty under MRP-planned manufacture - review and categorization. International Journal of Production Research, v. 40, n. 10, p. 2399-2421, 2002. 
KUMAR, S.; MEADE, D. Has MRP run its course? A review of contemporary developments in planning systems. Industrial management and Data Systems, v. 102, n. 8-9, p. 453-462, 2002.

LEACHMAN, R. C.; SOLORZANO, M.; GLASSEY, C. R. A queue management policy for the release of factory orders. University of California, Berkeley, Department of IE/OR, ESRC 88-19, December, 1988.

LEE, Y; ZIPKIN, P.: Tandem queues with planned inventories. Operations Research, v. 40, n. 5, p. 936-947, 1992.

LIAN, Z.; LIU, L. Continuous review inventory systems: models and heuristics. IIE Transactions, v. 33, n. 9, p. 809-822, 2001.

LIBEROPOULOS, G.; DALLERY, Y. Base stock versus WIP cap in single-stage make-to-stock production-inventory systems. IIE Transactions, v. 34, n. 7, p. 627-636, 2002.

LÖDDING, H. Dezentrale Bestandsorientierte Fertigungsregelung. (Thesis), University of Hannover, 2001.

LÖDDING, H.; YU, K. W.; WIENDAHL, H. P. Decentralized WIP-oriented manufacturing control (DEWIP). Production Planning \& Control, v. 14, n. 1, p. 42-54, 2003.

MACCARTHY, B. L.; FERNANDES,F. C. F. A multi-dimensional classification of production systems for the design and selection of production planning and control systems. Production Planning \& Control, v. 11, n. 5, p. 481-496, 2000.

MADDAH, B. S.; JABER, M. Y.; ABBOUD, N. E. Periodic review $(\mathrm{s}, \mathrm{S})$ inventory model with permissible delay in payments. Journal of the Operational Research Society, v. 55, n. 2, p. 147-159, 2004.

MELETON, M. P. OPT - fantasy or breakthrough ? Production and Inventory Management, v. 27, n. 2, p. 12-21, $2^{\text {nd }}$ quarter, 1986.

MELNYK, S. A.; VICKERY, S. K.; CARTER, P. L. Scheduling Sequencing and Dispatching - alternative perspectives. Production and Inventory Management, v. 27, n. 2, p. 58-68, $2^{\text {nd }}$ quarter, 1986.

MOLINDER, A. Joint optimization of lot sizes, safety stocks and safety leadtimes in am MRP system. International Journal of Production Research, v. 35, n. 4, p.983-994, 1997.

MONDEN, Y. Toyota Production System, Industrial Engineering and Management Press, Norcross, GA, 1993.

MURTHY, D. N. P.; MA, L. MRP with uncertainty a review and some extension. International Journal Production Economics, v. 25, n. 1-3, p. 51-64, 1991.

NARASIMHAN, S.; McLEAVEY, D. W.; BILLINGTON, P. Production Panning and Inventory Control. 2. ed. Englewood Cliffs (New Jersey): Prentice Hall, 1995.

NEUMAN, W.L. Social Research Methods, 5. ed. Boston: Allyn and Bacon, 2003

ORLICKY, J. Material Requirements Planning. New York (USA): McGraw-Hill, 1975.

OUYANG, L.; CHUANG, B.; LIN, Y. Impact of backorder discounts on periodic review inventory model. International Journal of Information and Management Sciences, v. 14, n. 3, p. 1-13, 2003.

OVALLE, O. R.; MARQUEZ, A. C. Exploring the utilization of a CONWIP system for supply chain management. A comparison with fully integrated supply chains. International Journal of Production Economics, v. 83, n. 2, p. 195-215, 2003.

PATERNINA-ARBOLEDA, C. D.; DAS, T. K. Intelligent dynamic control policies for serial production lines. IIE Transactions, v. 33 , n. 1 , p. $65-77,2001$
PLENERT, G. Focusing material requirements planning (MRP) towards performance. European Journal of Operational Research, v. 119, n. 1, p.91-99, 1999.

PRICE, W.; GRAVEL, M.; NSAKANDA, A. L. Review of optimization models of Kanban-based production systems. European Journal of Operational Research, v. 75, n. 1, p. 1-12, 1994.

PYKE, D. F.; FLEISCHIMANN, M.; MAHADEVAN, B. Periodic review, push inventory policies for remanufacturing. European Journal of Operational Research, v. 151, n. 3, p. 536-551, 2003.

REDA, H. M. Review of Kanban - the Japanese just in timeproduction system. Engineering Management International, v. 4, n. 2, p. 143-150, 1987.

RODERICK, L. M.; TOLAND, J.; RODRIGUES, F. P. Simulation study of CONWIP versus MRP at Westinghouse. Computers \& Industrial Engineering, v. 26, n. 2, p. 237-242, 1994.

SABUNCUOGLU, I.; KARAPINAR, H. Y. Analysis of order review/release problems in production systems. International Journal of Production Economics, v. 62, n. 3, p. 259-279, 1999.

SALAMEH, M. K. et al. Continuous review inventory model with delay in payments. International Journal of Production Economics, v. 85, n. 1, p. 91-95, 2003.

SCHONBERGER, R. J. Applications of single-card and dual-card kanban. Interfaces, v. 13, n. 4, p. 56-67, 1983.

SILVA, F. M. Um sistema de Planejamento e Controle da Produção para indústrias de calçados infantis pertencentes a um industrial cluster. Dissertação (Mestrado). Universidade Federal de São Carlos. São Carlos - SP, 2002.

SIPPER, D.; BULFIN JR., R.L. Production: Planning, Control and Integration, New York: Mc Graw Hill, 1997.

SIVASUBRAMANIAN, R.; SELLADURAI, V.; RAJAMRAMASAMY, N. The effect of the drum-bufferrope (DBR) approach on the performance of the synchronous manufacturing system (SMS). Production Planning and Control, v. 11, n. 8, p. 820-824, 2000.

SLACK, N.; CHAMBERS, S.; JOHNSTON, R. Administração da Produção. 2. ed., São Paulo: Ed. Atlas, 2002.

SO, K. C. The impact of buffering strategies on the performance of production line systems. International Journal of Production Research, v. 28, n. 12, p. 2293-2307, 1990.

SO, K. C.; PINAULT, S. C. Allocating buffer storages in a pull system. International Journal of Production Research, v. 15, n. 2, p. 1959-1980, 1988.

SPEARMAN, M. L. Customer Service in pull production systems. Operations Research, v. 40, n. 5, p. 53-63, 1992.

SPEARMAN, M. L.; WOODRUFF, D. L.; HOPP, W. J. CONWIP - a pull alternative to Kanban. International Journal of Production Research, v. 28, n. 5, p. 879-894, 1990.

STEELE,D.C.; MALHOTRA,M.K.:Factors affecting performance of period batch control systems in cellular manufacturing. International Journal of Production Research, v. 35, n. 2, p. 421-446, 1997

SUM, C. C.; ANG, J. S. K.; YEO, L. N. Contextual elements of critical success factors in MRP implementation. Production and Inventory Management Journal, v. 38, n. 3, p.77-82, $3^{\text {rd }}$ quarter, 1997.

SUM, C. C.; QUEK, S. A.; LIM, H. E. Analysing interaction effects on MRP implementation using ACE. International Journal of Production Economics, v. 58, n. 3, p.303-318, 1999.

SURI, R. Quick Response Manufacturing. Portland: Productivity Press, 1998. 
TAKAHASHI, K.; MYRESHKA, H. D. Comparing CONWIP, synchronized CONWIP, and Kanban in complex supply chains. International Journal of Production Economics, v. 93-94, special issue, p. 25-40, 2005.

TAKAHASHI, K.; NAKAMURA, N. Comparing reactive and reactive CONWIP. Production Planning \& Control, v. 13, n. 8, p. 702-714, 2002.

TARDIFF, V.; MAASEIDVAAG, L. An adaptive approach to controlling Kanban systems. European Journal of Operational Research, v. 132, n. 2, p. 411-424, 2001.

TAYUR, C. Properties of Serial Kanban systems. Queueing Systems, v. 12, p. 297-318, 1992.

URBAN, T. L. A periodic model with serially-correlated, inventorylevel-dependent demand. International Journal of Production Economics, v. 95, n.3, p. 287-295, 2005.

UZSOY, R.; MARTIN-VEGA, L. A. Modelling kanban-based demand-pull systems. A survey and critique, Manufacturing Review, v. 3, n. 3, p. 155-160, 1990.

VERGARA, S. C. Projetos e relatórios de pesquisa em administração. 5. ed. São Paulo: Atlas, 2004.

VOLLMAN, T. E.; BERRY, W. L.; WHYBARK, D. C. Manufacturing Planning and Control Systems, 4. ed. Mc Graw Hill, 1997.

WALKER, W. T. Practical application of drum-buffer-rope to synchronize a two stage supply chain. Production and Inventory Management Journal, v. 43, n. 3-4, p. 13-23, 2002 .
WHITE, R. E.; PRYBUTOK, V. The Relationship Between JIT practices and Type of Production System. Omega, The International Journal of Management Science, v. 29, p. 113-124, 2001.

WIENDAHL, H. P.; GLÄSSNER, J.; PETERMANN, D. Application of load-oriented manufacturing control in industry. Production Planning \& Control, v. 3, n. 2, p. 118-129, 1992.

WISNER, J. D. A review of the order release policy research. International Journal of Operations and Production Management, v. 15, n. 6, pp. 25-40, 1994.

WU, K. The effect of time-value of money on continuous review inventory model with controllable leadtime. International Journal of Management Sciences, v. 15, n. 2, p. 11-21, 2004.

YEUNG, J. H. Y.; WONG, W. C. K.; MA, L. Parameters affecting the effectiveness of MRP systems: a review. International Journal of Production Research, v. 36, n. 2, p. 313-331, 1998.

ZACCARELli, S. B. Programação e Controle da Produção. 8. ed. São Paulo: Ed. Pioneira, 1987.

ZAPFEL, G.; MISSBAUER, H. Production Planning and Control Systems including load-oriented order release - problems and research perspectives. International Journal of Production Economics, v. 30-31, p. 107-122, jul. 1993.

ZELENOVIC, D. M.; TESIC, Z. M. Period Batch Control and group technology. International Journal of Production Research, v. 26, n. 3, p. 539-552, 1988.

\section{Flávio Cesar Faria Fernandes Moacir Godinho Filho}

Departamento de Engenharia de Produção, Universidade Federal de São Carlos - UFSCar, Rod. Washington Luís, Km 235, CEP 13565-905, São Carlos, SP, Brasil,

e-mails: dfcf@ power.ufscar.br; moacir@dep.ufscar.br 